\title{
Forehead Skin Blood Flow in Normal Neonates during Active and Quiet Sleep, Measured with a Diode Laser Doppler Instrument
}

\author{
H. E. SUICHIES, ${ }^{1}$ J. G. AARNOUDSE,${ }^{1}$ A. OKKEN, ${ }^{1}$ H. W. JENTINK, ${ }^{2}$ \\ F. F. M. de $\mathrm{MUL}^{2}$ and J. GREVE ${ }^{2}$ \\ From the 'Department of Obstetrics and Pediatrics, University Hospital Groningen, Groningen, \\ and the 'Department of Applied Physics, Twente University of Technology, \\ Enschede. The Netherlands
}

\begin{abstract}
Suichies, H. E., Aamoudse, J. G., Okken, A., Jentink, H. W., de Mul, F. F. M. and Greve, J. (Departments of Obstetrics and Pediatrics, University Hospital, Groningen and Department of Applied Physics, Twente University of Technology, Enschede, The Netherlands). Forehead skin blood flow in normal neonates during active and quiet sleep, measured with a diode laser Doppler instrument. Acta Padiatr Scand 77: 220, 1988.

Changes in forehead skin blood flow during active and quiet sleep were determined in 16 healthy neonates using a recently developed semi-conductor laser Doppler flow meter without light conducting fibres. Measurements were carried out at a postnatal age varying from 5 hours to 7 days. The two sleep states could be distinguished in 17 recordings. The mean skin blood flow values during active sleep were significantly higher $(p<0.01)$ than those during quiet sleep, the mean increase being $28.1 \%$. The variability of the flow signal, expressed as the coeficient of variation, changed significantly from $23.1 \%$ during active sleep to $18.2 \%$ during quiet sleep. Key words: skin blood flow, laser Doppler, neonate, sleep state.
\end{abstract}

Data on the skin blood flow in the undisturbed neonate is scarce. This is obviously due to the lack of reliable non-invasive methods. Until now skin blood flow measurements in newborns were mostly performed using thermal $(1,2)$ or plethysmographic techniques $(3,4)$. The recently introduced laser Doppler flowmetry offers non-invasive, continuous measurement of the skin blood flow in a small tissue volume. The technique has an excellent response time and requires no heating of the skin. Laser Doppler measurements are, however, easily disturbed by movement of the optical fibres which connect the laser source and the detector to the skin. Recently we described a laser Doppler flow meter where the source, a small diode laser, and the detector are integrated in the probe (5). This laser Doppler flowmeter is less sensitive to movement artefacts and is, therefore, more suitable for measuring skin blood flow in active neonates. To date, no studies on changes in skin blood flow related to sleep states have been reported.

As many physiological phenomena change with behavioral state $(6,7,8,9,10,11)$, a study was undertaken to measure skin blood flow during active and quiet sleep in healthy full term neonates. Preliminary observations on the effects of aging on skin blood flow are also presented.

\section{PATIENTS AND METHODS}

Sixteen healthy fullterm infants were studied. They were born at a mean gestational age of 39.2 weeks (range 38 to 42 weeks) with a mean birthweight of $3530 \mathrm{~g}$ (range 2760 to $4380 \mathrm{~g}$ ). All had Apgar scores of a minimal of 6 after one minute and 8 after three minutes. Measurements of skin blood flow were carried out at a postnatal age varying from 5 hours to 7 days. Four neonates were measured twice with an interval of 3 to 5 days. None of the infants were receiving any medication and none of them had any clinical disturbances.

All measurements were performed at an environmental temperature of $28 \pm 0.5^{\circ} \mathrm{C}$ and a relative humidity of $60 \%$. Measurements were made half an hour after a feeding, with the infants lying clothed in their cots. The recordings lasted at least $50 \mathrm{~min}$, after a stabilisation period of 10 to $15 \mathrm{~min}$. The en- 

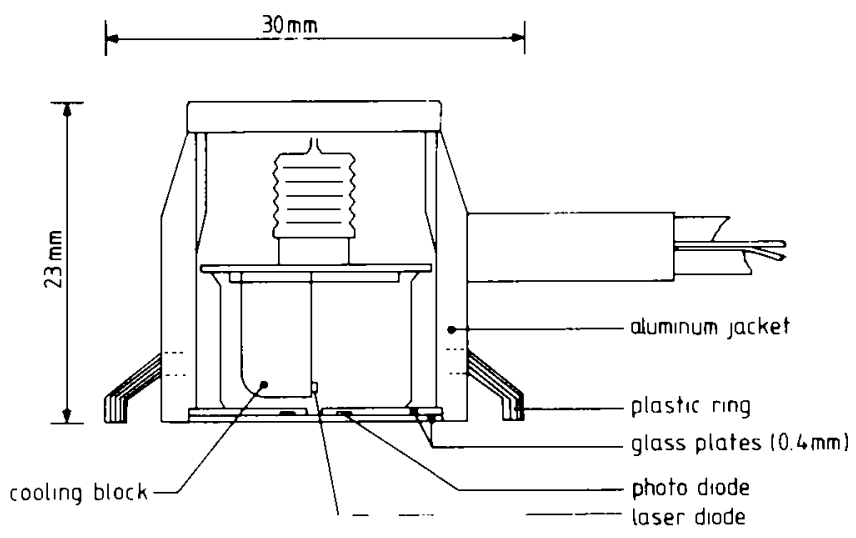

Fig. 1. The diode laser Doppler probe.

vironmental and skin temperature were measured continuously (Hewlett Packard 78214-A and Yellow Springs thermistor probes $409 \mathrm{~B}$ ). Skin temperature was measured behind the left or right earlobe and environmental temperature within a distance of $50 \mathrm{~cm}$ from the infant. Skin temperature changes did not exceed $0.3^{\circ} \mathrm{C}$ during the measurements.

Two different sleep states could be distinguished by observation using the criteria of Prechtl (10), state 1 (quiet or non-Rapid Eye Movement (N-REM) sleep), eyes closed, no movements apart from occasional startle reactions and a relatively regular respiration. and state 2 (active or REM sleep) eyes closed, frequent small body movements, rapid eye movements, "smiling", few mouth movements and a relatively irregular respiration. In analysing the data, movement artefacts, doubtful sleep state periods and sleep state periods lasting less than $3 \mathrm{~min}$ were not included. Periods of active and quiet sleep were observed in 17 of the 20 recordings. Quiet sleep was not observed in the other 3 . The total duration of quiet sleep time analysed for the flow measurements was $192 \mathrm{~min}$ and $284 \mathrm{~min}$ of active sleep.

Skin blood flow was measured according to the laser Doppler method described by others $(12,13,14)$. In short, this method is based on the following principle. Coherent laser light, illuminating the skin is scattered by static skin structures and moving particles, c.g. red blood cells. Scattered light from a moving particle, however, undergoes a frequency shift (Doppler principle). Backscattered Doppler shifted and unshifted light, mixed on a photodetector surface produce a frequency spectrum of beat notes, which is dependent on both the red blood cell velocity and the number of red blood cells. A differential detector system is used, and signal processing between $30 \mathrm{~Hz}$ and $30 \mathrm{kHz}$ provides an output in Volts, proportional to blood flow in vitro: We investigated this in a silicon model containing small channels with a diameter of $0.2 \mathrm{~mm}$, which was perfused by a solution of red blood cells.

In the present study an aluminum probe was used (Fig. 1) with a diameter of $22 \mathrm{~mm}$ and a height of $20 \mathrm{~mm}$ with a laser diode (RCA, $5 \mathrm{~mW}$ output at a wavelength of $832 \mathrm{~nm}$ ) and two photodiodes (BPX$40)$ integrated in the probe. The temperature increase of the skin caused by thermal effects of the diode laser Doppler probe was measured by placing a thermistor probe between the laser diode and the skin. The increase in thermistor temperature did not exceed $0.2^{\circ} \mathrm{C}$, and therefore thermal effects from the diode laser Doppler on the skin were neglected.

The flow-probe was positioned, in a plastic ring, on the skin. The total weight of the probe was $18 \mathrm{~g}$. Placed on a skin surface of $7.06 \mathrm{~cm}^{2}$, this means a local pressure of approximately $1.8 \mathrm{mmHg}$ on the skin underneath. This local pressure is very small in comparison with the intravascular blood pressure in the microvascular bed and therefore is unlikely to affect local blood flow. Skin blood flow was measured on

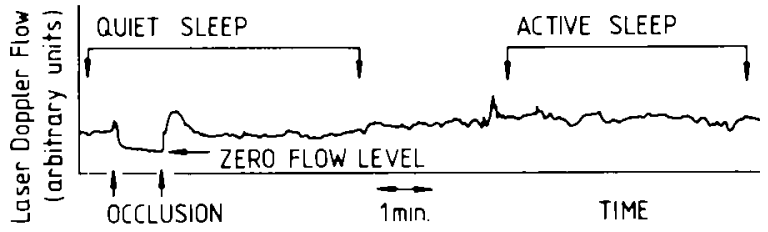

Fig. 2. Representative recording of skin blood flow during active and quiet sleep and a reactive hyperaemia after 1 min of arterial occlusion. 
the neonate's forehead, just below the hair implant. This place was chosen mainly for practical reasons, namely, that the forehead is an easily accessible area when neonates are lying under a blanket and it has a reasonably flat surface. In the present study the time constant of the instrument was set at $1.275 \mathrm{sec}$ to eliminate the short term fluctuations caused by the pulse waves. The laser Doppler signal and temperature signals were recorded on a 3 channel strip chart recorder (Linear 595) and on a tape recorder (Teac MR-30). The data were fed into a microcomputer for analysis (Apple II) at a sample frequency of $0.5 \mathrm{~Hz}$. The zero level of the flow signal was determined by local occlusion of the vascular bed which was achieved by pushing the probe against the skull. This procedure was carried out at least 4 times during a recording, at the beginning, at the end and during active and quiet sleep, and did not arouse the infant.

Flow values are presented in arbitrary units. For statistical analysis the $t$-test for paired and unpaired samples was used. Variation coefficient was chosen as an index of variability.

\section{RESULTS}

A representative recording of skin blood flow during active and quiet sleep is shown in Fig. 2. The mean flow value was significantly higher $(p<0.01)$ during active than during quiet sleep in all but 1 of the 17 recordings (Fig. 3), the mean increase being $28.1 \%$ (range -1.3 to +76.5 ) (Fig. 3, Table 1). The difference between the flow values in active and quiet sleep was not influenced by the order in which the two states of sleep occurred.

There was a marked increase in the variability of the flow signal during active sleep compared to quiet sleep. The variation coefficient increased significantly $(p<0.01)$ from $18.2 \%$ during quiet sleep to $23.1 \%$ during active sleep, the mean increase being $17.9 \%$ (range -7.4 to +57.3 ) (Table 1).

Table 1. Summary of 20 recordings of skin blood flow measurements in 16 newborn infants Laser Doppler skin blood flow values are presented in arbitrary units (mean $\pm S D$ ), the variability is expressed as the coefficient of variation (C. V.)

\begin{tabular}{|c|c|c|c|c|c|c|c|c|c|c|}
\hline \multirow{4}{*}{$\frac{\text { No. }}{1}$} & \multirow{4}{*}{$\begin{array}{l}\begin{array}{l}\text { Age } \\
\mathrm{h}=\text { hour } \\
\mathrm{d}=\text { day }\end{array} \\
5 \mathrm{~h}\end{array}$} & \multirow{4}{*}{$\begin{array}{l}\begin{array}{l}\text { Weight } \\
(\mathrm{g})\end{array} \\
3290\end{array}$} & \multicolumn{6}{|c|}{ Laser Doppler skin blood flow } & \multirow{4}{*}{$\begin{array}{l}\begin{array}{l}\% \text { incr. } \\
\text { mean } \\
\text { blood } \\
\text { flow }\end{array} \\
30.8\end{array}$} & \multirow{4}{*}{$\begin{array}{l}\% \text { incr. } \\
\text { C. V. } \\
23.5\end{array}$} \\
\hline & & & \multicolumn{3}{|c|}{ Active sleep } & \multicolumn{3}{|c|}{ Quiet sleep } & & \\
\hline & & & \multicolumn{2}{|c|}{ Mean \pm SD } & \multirow{2}{*}{$\frac{\text { C. V. }}{33.1}$} & \multicolumn{2}{|c|}{ Mean \pm SD } & \multirow{2}{*}{$\frac{\text { C. V. }}{25.3}$} & & \\
\hline & & & 6.8 & 2.25 & & 4.7 & 1.19 & & & \\
\hline 2 & $7 \mathrm{~h}$ & 3760 & 6.4 & 1.36 & 21.1 & 3.3 & 0.59 & 17.9 & 38.9 & 15.6 \\
\hline \multirow[t]{2}{*}{3} & $7 \mathrm{~h}$ & 4190 & 16.9 & 4.19 & 24.8 & 12.7 & 2.34 & 18.6 & 25.4 & 25.0 \\
\hline & $14 \mathrm{~h}$ & 3520 & 37.4 & 4.49 & 12.0 & & & & & \\
\hline 4 & $15 \mathrm{~h}$ & 4380 & 29.4 & 7.08 & 24.1 & 14.1 & 1.45 & 10.3 & 52.4 & 57.3 \\
\hline 5 & $17 \mathrm{~h}$ & 3405 & 7.8 & 1.90 & 24.3 & 6.3 & 1.62 & 25.7 & 19.2 & -5.4 \\
\hline \multirow[t]{2}{*}{6} & $20 \mathrm{~h}$ & 3380 & 7.9 & 1.49 & 18.9 & 8.0 & 1.36 & 17.0 & -1.2 & 10.0 \\
\hline & $1 \mathrm{~d}$ & 3755 & 5.7 & 1.18 & 20.7 & & & & & \\
\hline 7 & $1 \mathrm{~d}$ & 3200 & 11.2 & 3.02 & 27.0 & 8.8 & 1.24 & 14.1 & 21.4 & 47.7 \\
\hline 8 & $1 \mathrm{~d}$ & 3390 & 43.9 & 4.29 & 9.8 & 37.6 & 3.23 & 8.6 & 14.4 & 12.2 \\
\hline 9 & $2 \mathrm{~d}$ & 2750 & 7.8 & 2.39 & 30.6 & 7.7 & 1.53 & 19.9 & 1.3 & 35.0 \\
\hline 10 & $4 \mathrm{~d}$ & 3235 & 18.8 & 5.48 & 29.1 & 16.4 & 3.62 & 22.1 & 12.8 & 24.0 \\
\hline 11 & $4 d$ & 3330 & 18.4 & 6.00 & 32.6 & 13.8 & 3.13 & 22.7 & 25.0 & 30.4 \\
\hline 12 & $5 \mathrm{~d}$ & 3130 & 28.8 & 4.67 & 16.2 & 19.4 & 3.39 & 17.5 & 32.8 & -7.4 \\
\hline 13 & $5 \mathrm{~d}$ & 3975 & 23.8 & 3.72 & 15.6 & 5.6 & 0.52 & 9.2 & 76.5 & 12.4 \\
\hline 14 & $5 d$ & 3165 & 15.1 & 3.49 & 26.1 & 8.1 & 1.98 & 24.4 & 47.0 & 11.2 \\
\hline \multirow[t]{2}{*}{15} & $5 d$ & 3050 & 20.4 & 3.90 & 19.1 & 12.6 & 2.27 & 18.0 & 38.2 & 5.4 \\
\hline & $6 \mathrm{~d}$ & 2760 & 28.7 & 5.17 & 18.0 & & & & & \\
\hline 16 & $6 \mathrm{~d}$ & 4235 & 44.4 & 10.4 & 23.4 & 25.3 & 5.97 & 23.6 & 44.6 & -0.5 \\
\hline 17 & $7 \mathrm{~d}$ & 3270 & 23.7 & 3.97 & 16.6 & 24.0 & 3.59 & 14.9 & -1.3 & 7.2 \\
\hline
\end{tabular}




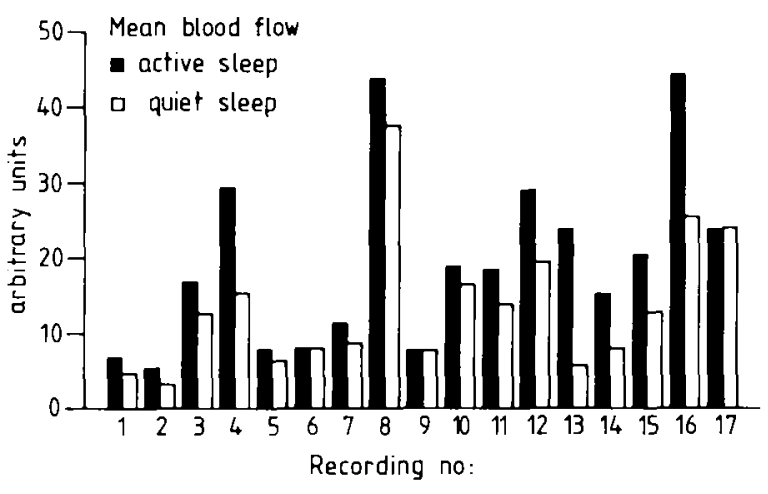

Fig. 3. Histogram showing the differences in skin blood flow during quiet and active sleep in 17 recordings. The number correspond to the numbers in the table.

An increase in the difference between the skin blood flow in active and in quiet sleep was found in older neonates ( 2 to 7 days old) than in younger ones (up to 2 days old). This increase was mainly the result of a higher skin blood flow during active sleep, which was on average $37 \%$ higher. The difference did not, however, reach the level of statistical significance.

\section{DISCUSSION}

The results of the present study indicate that, in normal neonates, forehead skin blood flow is higher during active sleep than during quiet sleep and that there is an increased variability in skin blood flow in active sleep.

Changes in skin blood flow associated with different sleep states have, to the best of our knowledge, not been described previously. Strömberg et al. (15) using a conventional fibreoptic laser Doppler flow meter, found an increase in skin blood flow with increasing activity. Storrs (16) measured total limb blood flow by venous occlusion plethysmography in premature infants and showed an increased variability during irregular breathing but could not demonstrate significant blood-flow changes associated with different sleep states. Brück et al. (1) reported quite large changes in skin blood flow, during the first hours of life, associated with thermolability.

Changes in environmental temperature and humidity have a considerable effect on skin blood flow. In this study the changes in environmental temperature and humidity were, however, found to be very small and cannot, therefore, explain the observed increase in skin blood flow during active sleep.

It has been shown that there is an increase in metabolic activity in active sleep as compared to quiet sleep. This increase which is also reflected by an increased oxygen consumption, results in an increased heat production (17). As a result, thermoregulation increases subpapillary skin blood flow and this seems the most likely explanation for the higher skin blood flow during active sleep.

Hagbarth et al. (18) and Delius et al. (19) described the influence of sympathetic activity on skin blood flow in adults. This factor as well as thermoregulation probably also influences skin blood flow variability in neonates. It seems evident, that autonomic controlled functions are much more variable during active than during quiet sleep. Respiration rate and respiration volume were found to be more variable in active than in quiet sleep (6). Increased respiratory movement is associated with a higher sympathetic outflow (19). A more irregular respiration could therefore result in a variable skin blood flow during active sleep. It seems likely that the increased variability of forehead skin blood flow in active sleep could, at least 
partly, be attributed to a more variable autonomic activity. The more variable metabolic activity in active sleep, which has also been demonstrated by Stothers \& Warner (11), probably results in a more variable heat procuction, which might also contribute to the greater variability in skin blood flow.

The diode laser Doppler instrument used in this study, has advantages over the conventional He-Ne laser Doppler instruments. The lack of light conducting fibres is of particular importance in neonates because these fibres can easily produce movement artefacts in the laser Doppler signal. Theoretically, both the wave length of $832 \mathrm{~nm}$ and the larger distance between laser beam and photodiodes should result in a slightly larger measuring volume, as compared to the Periflux laser Doppler flowmeter, using a He-Ne laser $(20,21,22)$. On the other hand, this effect will be compensated by the more diverging laser beam of the laser diode. Despite the differences, the diode laser Doppler flow meter produces skin blood flow tracings comparable to those of the Periflux He-Ne laser Doppler flow meter during comparative measurements (unpublished results). It can be concluded from this study that the slecp state of the neonate must be taken into account when measuring skin blood flow of the forehead skin.

\section{ACKNOWLEDGEMENT}

This study was supported by the Netherlands Technology Foundation.

\section{REFERENCES}

I. Brück K, Brück M, Lemtis $\mathrm{H}$. Hautdurchblutung und Thermoregulation bei neugeborenen Kindern. Pflügers Arch 1957; 265:55-65.

2. Berg K. Celander $\mathrm{O}$. Circulatory adaptation in the thermoregulation of fulterm and premature newborn infants. Acta Paediatr Scand 1971; 60: 278-84.

3. Wallgren G. Lind J. Quantitative studies of the human neonatal circulation. Acta Paediatr Scand 1967; Suppl 179.

4. Celander $O$, Märild $K$. Regional circulation and capillary filtration in relation to capillary exchange in the foot and calf of the newborn infant. Acta Paediat Scand 1962; 51:385-400.

5. de Mul FFM, van Spijker J, van der Plas D, Greve J, Aarnoudse JG, Smits TM. Mini laser Doppler (blood) flow monitor with diode laser source and detection integrated in the probe. Appl Optics 1984; 23: 2970-73.

6. Bolton DP, Herman S. Ventilation and sleep states in the newborn. J Physiol 1974; 240: 67.

7. Hanson N, Okken A. Transcutaneous oxygen tension of newborn infants in different behavioral states. Pediatr Res 1980; 14: 911-15.

8. Kariam R, Shultze K, Koeningsberger M, James LS. The effects of changing sleep states on autonomic functions in the newborn. Pediatr Res 1979; 13: 498.

9. Martin MJ, Okken A. Arterial oxygen tension during active and quiet sleep in the normal neonate. J Pediatr 1979; 94: 271-74.

10. Prechtl HFR. The behavioral states of the newborn infant (a review). Brain Res 1974; $76: 185$.

11. Stothers JK. Warner RM. Oxygen consumption and neonatal sleep states. J Physiol 1978; 278: 43540.

12. Nilson GE. Tenland T, Oberg PA. Evaluation of a laser Doppler flow meter for measurement of tissue blood flow. IEEE Trans Biomed Eng 1980; 27: 12-19.

13. Stern MD, Lappe DL, Bowen PD et al. Continuous measurement of tissue blood flow by laser Doppler spectroscopy. Am J Physiol 1977; 232: 441-48.

14. Wunderlich RW, Folger RL, Giddon DB, Ware BR. Laser Doppler blood flow meter and optical plethysmograph. Rev Sci Instrum 1980; 51 (9): 1258-62.

15. Strömberg B, Riesenfeld T, Sedin G. Laser Doppler measurements of skin blood flow in newborn infants. Int $J$ Microcirc Clin Exp 1984; 3:326.

16. Storrs CN. Cardiovascular effects of apnoea in preterm infants. Arch Dis Child 1977; 52:534-40.

17. Stothers JK, Warner RM. Thermal balance and sleep state in the newborn. Early Hum Dev 1984; 9: $313-322$. 
18. Hagbarth KE, Hallin RG. Hongell A, Torebjörk HE, Wallin BG. General characteristics of sympathetic activity in human skin nerves. Acta Physiol Scand 1972; 84: 164-76.

19. Delius W, Hagbarth KE, Hongell A, Wallin BG. Manoeuvres affecting sympathetic outflow in human skin nerves. Acta Physiol Scand 1972; 84: 177-86.

20. Kolari PJ. Penetration of unfocused laser light into the skin. Arch Dermatol Res 1985; 277: 342-44.

21. Gush RJ, King TA, Jayson MIV. Aspects of laser light scattering from skin tissue with application to laser Doppler blood flow measurements. Phys Med Biol 1984; 29: 1463-76.

22. Duteil L, Bernengo JC, Schalla W. A double wavelength laser Doppler system to investigate skin microcirculation. IEEE Trans Biomed Eng 1985; 32 (6): 439-47.

(J. G. A.) Department of Obstetrics

University Hospital Groningen

Oostersingel 59

9713 EZ Groningen

The Netherlands 